\title{
Gum Arabic Improves Reproductive Function Associated with Alteration of Testicular Visfatin mRNA Expression in Alloxan Induced Diabetic Rats
}

\author{
Abdelkareem A Ahmed ${ }^{1,2 *}$, Adriano Mollica ${ }^{2,3}$, Azzurra Stefanucci ${ }^{2,3}$, Gokhan Zengin ${ }^{2,4}$, \\ Mohammed Elmujtba Adam Essa ${ }^{2}$, Abubakr Hassan ${ }^{2}$ and Hussein Ahmed ${ }^{5}$ \\ ${ }^{1}$ Department of Physiology and Biochemistry, Faculty of Veterinary Science, University of Nyala, Nyala, Sudan \\ ${ }^{2}$ Department of Clinical Medicine, Medical and Cancer Research Institute, Nyala, Sudan \\ ${ }^{3}$ Department of Pharmacy, University “G. d'Annunzio" of Chieti-Pescara, Chieti, Italy \\ ${ }^{4}$ Department of Biology, Science Faculty, Selcuk University, Konya, Turkey \\ ${ }^{5}$ College of Veterinary and Animal Science, the Islamia University, Bahawalpur, Pakistan \\ *Corresponding author: Abdelkareem A Ahmed, Department of Physiology and Biochemistry, Faculty of Veterinary Science, \\ University of Nyala, Nyala, 583, Sudan
}

\section{ARTICLE INFO}

Received: 㓞July 23, 2021

Published: 幽 August 03, 2021

Citation: Abdelkareem A Ahmed, Adriano Mollica, Azzurra Stefanucci, Gokhan Zengin, Mohammed Elmujtba Adam Essa, et al., Gum Arabic Improves Reproductive Function Associated with Alteration of Testicular Visfatin mRNA Expression in Alloxan Induced Diabetic Rats. Biomed J Sci \& Tech Res 37(4)-2021. BJSTR. MS.ID.006041.

Keywords: Gum Arabic; Rat; Testis; Type I Diabetes; Visfatin

Abbreviations: DM: Diabetes Mellitus; LH: Luteinizing Hormone; FSH: Follicular Stimulating; GA: Gum Arabic; SD: Sprague-Dawley; NTC: No Template Controls; H\&E: Hematoxylin and Eosin; LSD: Least-Significant Difference

\section{ABSTRACT}

Objectives: Diabetes mellitus (DM), an endocrine disorder, epidemic all over the world which causes dysfunction of reproductive capacity. Gum Arabic (GA), a dietary fibre has potential health effects on reproductive system. Visfatin is one of the adipokines which has a crucial role in reproductive function.

Aims: We hypothesized that the testicular Visfatin may be affected by administration of GA in diabetic rat.

Material and Methods: Sixty male Sprague-Dawley rats were divided into 3 groups $(n=20$ of each): control group, diabetic group which were injected with Alloxan, and diabetic group given $10 \% \mathrm{GA}$ in the form of drinking water for 8 weeks. The sperm quality, blood glucose, serum testosterone were measured. In addition, both testicular mRNA and protein expression of Visfatin were measured. Moreover, testicular histopathological features were examined.

Results: The treatment of GA significantly $(\mathrm{P}<0.05)$ improved semen quality compared the diabetic and control groups. The treatment of GA significantly $(\mathrm{P}<0.05)$ decreased blood glucose concentrations whereas, increased serum testosterone concentrations when compared to diabetic and control groups. In addition, treatment of GA significantly $(\mathrm{P}<0.05)$ increased testicular Visfatin mRNA expression associated with upregulation of Visfatin protein expression compared to the diabetic group. Testis of diabetic rats showed obvious degeneration whereas; slight degeneration was seen in GA treated rats compared to control. Visfatin mRNA expression revealed a positive correlation with body, testis weight and serum testosterone concentrations, while a negative correlation was observed with blood glucose concentrations.

Conclusion: Our findings conclude that GA may improve reproductive performance and it may be useful to meliorate the diabetic fertility complications in male. 


\section{Introduction}

Bioactive natural principles are reported used as a source of medicinal agents for several decades [1,2]. Herbal-based principles play vital roles in the treatment the prevention of diabetes mellitus (DM) $[3,4]$. In developing countries, herbal products considered as a traditional medicine for meliorating diabetes complications $[5,6]$. Approximately, fifty millions of couples worldwide are experience infertility problems $[7,8]$, mainly through comparative contributions in change of lifestyle [9] and metabolic disorder factors [10]. Herbal bioactive agents are principally used worldwide to improve reproductive capacity [11]. Various types of medicinal plants are reported to be used in mixture with assisted reproductive technologies [11,12] to decrease the cost $[13,14]$ and boost infertility success rate [15]. DM is a group of metabolic disorders that characterized by hyperglycemia [16] due to the defects in secretion of insulin, insulin action, or both [17]. The chronic hyperglycemia in diabetes patients is reported to be associated with long-term tissue damage [18], dysfunction [18], and failure of various organs [19], in particular the reproductive organs [20]. The prolonged hyperglycemia is associated with protracted dysfunction [21], damage, and collapse of functioning of a variety of organs, including kidneys [22], and blood vessels [23], nerves [24], and testis [25,26]. Hyperglycaemia trigger reactive oxygen species production [27], which in turn causes cell damage via different mechanisms [28-30]. Both tissues and cellular damage ultimately consequences in the secondary complications of DM [31].

Many experimental and clinical reports have been conducted on the molecular mechanisms responsible for the changes induced by DM in reproductive system of male but much remains to be clarified [32]. Some studies implicated that the diabetes induced male infertility through histological damage of the epididymis [33], decreased sperm motility [34], semen volume [35], sperm counts, motility and morphology [36] and disruption of seminiferous tubular morphology [37]. Moreover, DM induced male infertility via decreasing serum levels of luteinizing hormone (LH), follicular stimulating (FSH) [38] and testosterone [39]. Visfatin, a newly is adipocyte hormone that discovered, that has strong relationship with type 2 diabetic patients [40]. Visfatin is found to bind to the insulin receptor at a site different from that of insulin causes hypoglycaemia [41] by reducing glucose release from liver cells [42] and stimulating glucose utilization in adipocytes [43] and myocytes [44]. Visfatin is upregulated by hypoxia in adipocytes [45], inflammation and hyperglycemia and downregulated by insulin, somatostatin and statins. Previous studies reported that plasma levels and tissue expression of visfatin increased in parallel with diabetes [46]. Visfatin was reported to have insulin-mimetic effects [47] and lowers plasma glucose levels [48]. In addition, high glucose concentrations obviously increased visfatin production in cultured adipocytes [49]. Moreover, blood visfatin levels were found to increase in parallel with hyperglycemia [46]. Moreover, it is reported that type 2 diabetic patients found to have elevated plasma visfatin concentrations [50]. On the other hand, plasma visfatin concentrations were reported to be decreased in diabetic women during gestational period [51]. Visfatin plasma levels together with its expression were found to be associated with obesity [52], insulin resistance [53] and type 2 diabetic patients [54].

Gum Arabic (GA) from Acacia seyal and Acacia senegal, is dried sticky exudate that contains soluble dietary fiber [55]. It is commonly used in food industry [56] and pharmaceutical preparations [57] as preservative and emulsifier [58]. Several studies confirmed that GA lowers blood cholesterol [59], improves antioxidant capacity [60] decreases blood glucose [61], decreases blood pressure in patients with type 2 DM patients [62]. However, the effects of GA on Visfatin in testis of type I diabetic rats have not been reported. In addition, it is less clear whether GA may modify testosterone levels in type I diabetic rats. Therefore, in the present study, we induced type I diabetic in rat to elucidate our hypothesis that the treatment of GA to type I diabetic rat may change blood Visfatin and its mRNA and protein in the testis of diabetic rat and the changes in Visfatin may correlate with blood glucose, testosterone concentrations, testis and body weight in diabetic rat.

\section{Materials and Methods}

\section{Animals and Experimental Design}

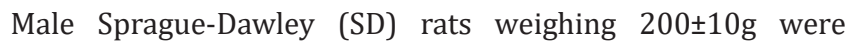
purchased Sudanese National Center for Research and housed in a controlled environment with a $12 \mathrm{~h}$ light-dark cycle. Animals were acclimatized for one week before the study and had free access to water and standard rat chow throughout the experimental period. The rats were divided into 3 groups: control group $(n=20)$ given standard animal pellet and water ad libitum; diabetic group $(n=20)$; and diabetic group $(n=20)$ given $10 \%$ Gum Arabic in drinking water for 8 weeks. Type I diabetes mellitus was induced as described by Adeyi, et al. [63]. Briefly, Alloxan monohydrate was purchased from Sigma-Aldrich China (Shanghai, China), and type I diabetes mellitus was induced by single intraperitoneal injection of $150 \mathrm{mg} / \mathrm{kg}$ of Alloxan monohydrate dissolved in normal saline after an overnight fast. Surviving rats after 3 days with blood glucose concentration more than $200 \mathrm{mg} / \mathrm{dl}$ of blood were considered as Alloxan-induced diabetic rats and used as type I diabetic models rat for further study. All rats were euthanized after 8 weeks of treatment. On day 70 , the rats were fasted overnight, urine and blood samples were collected prior to euthanasia. Body weights and organ weights were recorded; blood and tissue samples were collected and stored at $-80{ }^{\circ} \mathrm{C}$ until analyzed. The experiment procedures were approved by the Animal Ethics Committee of University of Nyala. 


\section{Sperm Analysis}

Testes with epididymis were removed, and the caudal epididymidis were separated from the testis and the semen was collected. Squeezed semen was incubated in buffer containing BSA at $37{ }^{\circ} \mathrm{C}$ for 30 minutes. The normal morphology of sperm, motility, sperm count and its viability were measured in groups of experimental rats. We used Makler Chamber and light microscopy (Olympus Co., Tokyo, Japan) for sperm movement analysis. The motility was expressed as the percentages of progressive motility including rapid (Grade a) and slow (Grade b) spermatozoa, nonprogressive (Grade c) and immotile (Grade d) spermatozoa. The morphology of the spermatozoa was evaluated using the original dilution for motility, diluted 1:20 with 10\% neutral buffered formalin. The sperms were classified according to the presence of one or more abnormal features such as tail defect (colloid, irregular, Short, or multiple tails); neck and middle piece (bend middle piece, distended irregular, abnormality thin middle piece); and head defects (small or large size, round head, double or detached head). The data were presented as percentage of morphological normal sperm.

\section{Blood Glucose}

Serum was obtained from blood by centrifugation (at 3000rpm for $15 \mathrm{~min}$ ) and stored at $-20 \stackrel{\circ}{\circ} \mathrm{C}$ until analyzed. Blood glucose was measured using assay kits (Nanjing Jiancheng Bioengineering Company, Nanjing, China), according to the manufacturers' instructions.

\section{Plasma Testosterone}

After decapitation of rats, blood was collected from the ruptured cervical vessels in new heparinized tubes for plasma testosterone measurement. The plasma was obtained after centrifugation $\left(2,400 \mathrm{rpm}, 20 \mathrm{~min}, 3.5^{\circ} \mathrm{C}\right)$ in a refrigerated device and frozen at $-20{ }^{\circ} \mathrm{C}$ until measurement of hormone levels. Plasma testosterone concentrations were measured by radioimmunoassay method, using the Testosterone Maia ${ }^{\circledR}$ kit (Biochem Immuno System) according to the manufacturers' instructions. All plasma samples were dosed in the same assay, to avoid inter-assay errors. The lower detection limit for testosterone was $0.064 \mathrm{ng} / \mathrm{mL}$, with a $4 \%$ intraassay error.

\section{Real-Time PCR and Gene Expression}

About $100 \mathrm{mg}$ of liver was ground in liquid $\mathrm{N}_{2}$, and a portion of about 50mg was used for RNA extraction using TRIzol total RNA kit (Invitrogen, Biotechnology Co, Ltd, Carlsbad, CA, USA) according to the manufacturer's instruction. Two approaches were taken to ensure that all the total RNA preparations are free of genomic DNA contamination. Firstly, total RNAs were treated with 10 U DNase I (RNase Free, D2215, Takara, Japan) for $30 \mathrm{~min}$ at $37^{\circ} \mathrm{C}$, and purified according to the manufacturer's protocol. Secondly, the primers for the reference gene (GAPDH) were designed to span an intron, so any genomic DNA contamination could be reported easily with an extra product in the melting curves for real-time PCR. Real-time PCR was performed in Mx3000P (Stratagene, USA) according to our previous publications [64]. Mock RT and No Template Controls (NTC) were included to monitor the possible contamination of genomic and environmental DNA at both RT and PCR steps. The pooled sample was made by mixing equal quantity of RT products (cDNA) from all samples and was used for optimizing the PCR condition and tailoring the standard curves for each target gene. The melting curves were performed to insure a single specific PCR product for each gene. The PCR products were sequenced to validate the identity of the amplicons. Primers specific for Visfatin (Table 2) was synthesized by Geneary (Shanghai, China). Rat GAPDH was used as a reference gene for normalization purpose. The method of $2^{-\Delta \Delta C t}$ was used to analyze the real-time PCR data [65]. The mRNA abundances were presented as the fold change relative to the average level of the control group.

Table 1.

\begin{tabular}{|c|c|c|}
\hline Variable & Control & Diabetic \\
\hline Sperm Quality Count (x106) & $109.3 \pm 65.3 \mathrm{a}$ & $26.98 \pm 6.51 \mathrm{~b}$ \\
\hline Rapid mobility (\%) (Grade a) & $23.16 \pm 9.03 \mathrm{a}$ & $9.24 \pm 1.36 \mathrm{~b}$ \\
\hline Slow mobility (\%) (Grade b) & $28.64 \pm 5.1 \mathrm{a}$ & $18.35 \pm 6.04 \mathrm{~b}$ \\
\hline $\begin{array}{c}\text { Non progress mobility (\%) (Grade } \\
\text { c) }\end{array}$ & $34.0 \pm 5.6 \mathrm{a}$ & $20.78 \pm 4.6 \mathrm{~b}$ \\
\hline Immotile sperm (\%)(Grade d) & $27.06 \pm 8.86 \mathrm{a}$ & $58.3 \pm 5.69 \mathrm{~b}$ \\
\hline Total motility (\%) (Grade a, b, c) & $79.30 \pm 7.54 \mathrm{a}$ & $48.79 \pm 5.18 \mathrm{~b}$ \\
\hline Normal morphology & $80.6 \pm 12.05 \mathrm{a}$ & $38.1 \pm 3.8 \mathrm{c}$ \\
\hline Viability (\%) & $84.05 \pm 7.52 \mathrm{a}$ & $50.56 \pm 4.76 \mathrm{~b}$ \\
\hline
\end{tabular}


Table 2.

\begin{tabular}{|c|c|c|c|}
\hline Target Genes & Genbank Accession Number & PCR Products & Primer Sequences \\
\hline Visfatin & NM_177928.3 & 348 & $\begin{array}{l}\text { F : 5'- TGCTACTGGCTCACCAACTG-3' } \\
\text { R : 5'- GTCTTTCCCCCACGCTGTTA -3' }\end{array}$ \\
\hline GAPDH & NM_008084.2 & 141 & $\begin{array}{l}\text { F: 5'- ACATGGTCTACATGTTCCAGTA-3' } \\
\text { R: 5'- GGAGTCTACTGGTGTCTTCA-3' }\end{array}$ \\
\hline
\end{tabular}

\section{Protein Extraction and Western Blot Analysis}

Protein extracts from $50 \mathrm{mg}$ of frozen liver tissue were prepared as described in our previous publication [66]. The protein concentrations were measured by Pierce BCA Protein Assay Kit (Thermo Scientific, USA). Western blot analysis for Visfatin (Cayman Chemical Company, USA, diluted 1:200) and Visfatin (sc20176, Santa Cruz Biotechnology, USA, diluted 1:200) were carried out according to the recommended protocols that offered by the company. B-actin (Cayman Chemical Company, USA, and diluted 1:10.000) was used as a reference in the Western blot analysis.

\section{Histopathology Examinations}

Livers were fixed in paraformaldehyde solution and embedded in paraffin, sectioned serially at $4 \mathrm{~lm}$ and stained with hematoxylin and eosin (H\&E) to investigate the morphologic changes in control, diabetic and diabetic rats treated with Gum Arabic. Slides at every time-point were stained with H\&E and observed under a light microscope (Nikon, Tokyo, Japan).

\section{Statistical Analysis}

Descriptive statistics analysis was made to check the normality and homogeneity of variances before parametric analyses. Body weight, organs weight, semen parameters, blood glucose, plasma testosterone, relative quantitative data of gene expression, in addition to western blot analysis data were statistically analyzed by one-way ANOVA using IBM SPSS statistics 21.0 for Windows, followed by a least-significant difference (LSD) test for individual comparisons. A P-value $\leq 0.05$ was considered significant.

\section{Results}

\section{Effect of GA Treatment on Food Intake, Body Weight and Organs Weight}

In the present study, Alloxan induced diabetic rat groups showed significantly increases in food intake compared to the control group. The treatment of GA significantly $(\mathrm{P}<0.05)$ decreased food intake (Figure 1A). No significant differences were observed final body weight (Figure 1B), testis weight (Figure 1C) and epididymis weight (Figure 1D) regarding the treatment of GA.

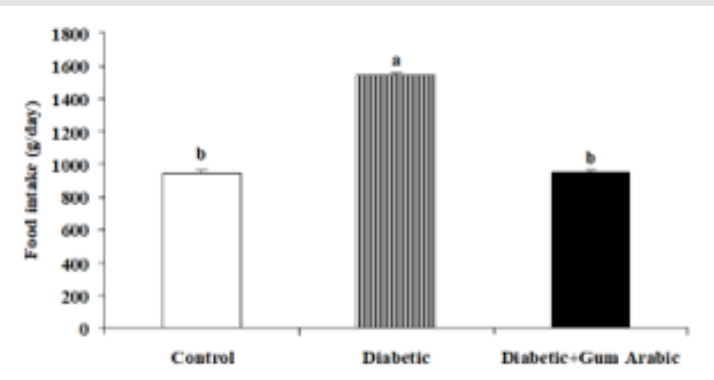

A

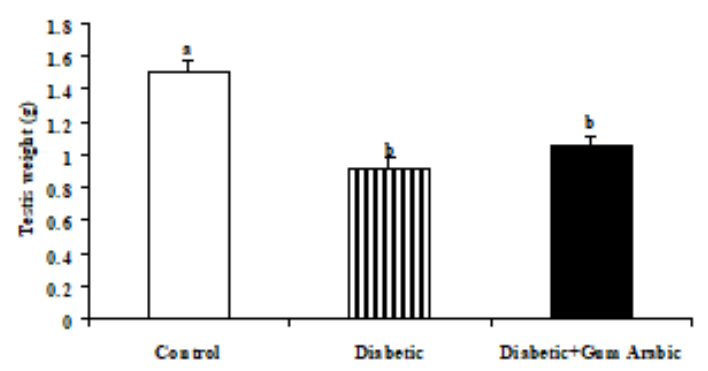

C

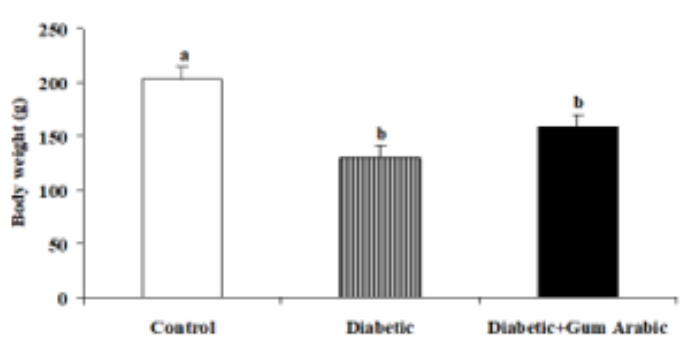

B

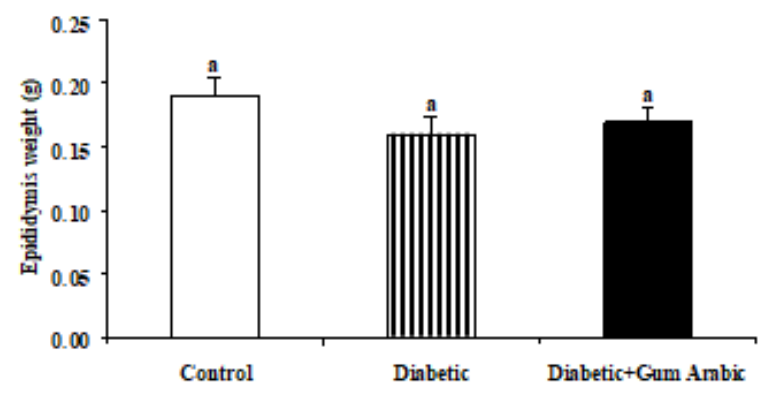

D

Figure 1. 
Blood Glucose, Serum Testosterone and Visfatin Concentrations

Treatment of GA significantly $(\mathrm{P}<0.05)$ decreased blood glucose concentrations compared to the control and diabetic groups (Figure 2A). In contrast, the treatment of GA significantly $(\mathrm{P}<0.05)$ increased serum testosterone concentration compared to the diabetic rat group (Figure 2B). Likewise, the treatment of GA significantly increased serum Visfatin concentration compared to the diabetic rat group (Figure 2C).

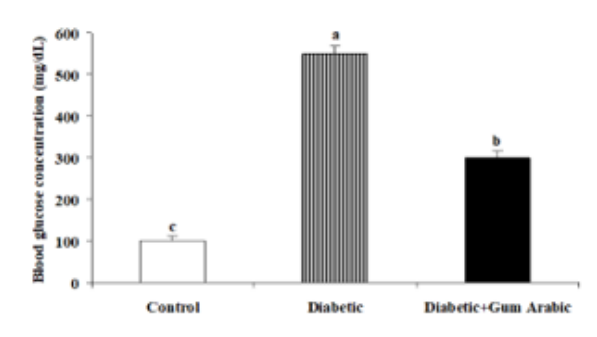

A

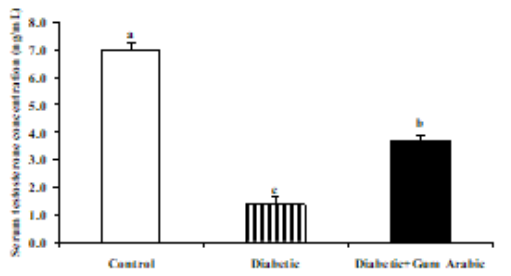

B

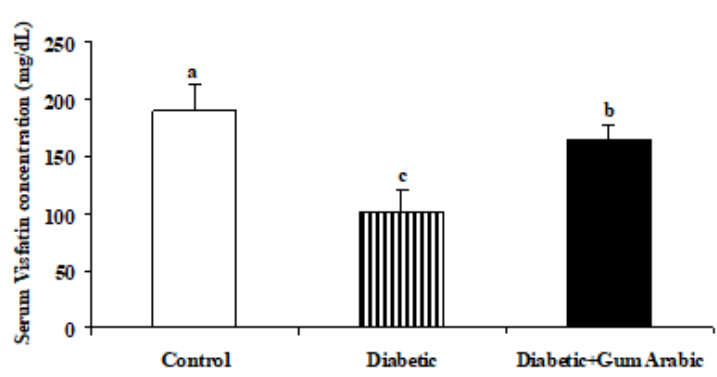

C

Figure 2.

\section{Parameters Correlations}

The present study, expression of Visfatin mRNA revealed a positive correlation with body weight (Figure 3A), testis weight (Figure 3B), and serum testosterone concentration (Figure 3D). However, the expression of Visfatin showed negative correlation with blood glucose concentrations (Figure 3C).

\section{Effect of GA Treatment on Semen Quality}

Alloxan induced diabetic rat group showed significant decreases in sperm count, sperm rapid mobility, slow motility, non-progress mobility, total motility and sperm vitality compared to the control. However, the treatment of GA significantly $(\mathrm{P}<0.05)$ improved the above mentioned sperm quality parameters. On the other hand, diabetic rat group showed significant increases in immotile sperm compared to the control group. But the treatment of GA significantly
$(\mathrm{P}<0.05)$ reduced immotile sperm compared to that in diabetic rat (Table 1).

\section{Testicular Visfatin mRNA Expression}

In the current study, the treatment of Alloxan significantly reduced testicular mRNA expression of Visfatin compared to the control group. But the treatment of GA significantly $(\mathrm{P}<0.05)$ upregulated testicular Visfatin mRNA expression compared to the diabetic rat group (Figure 4A).

\section{Testicular Visfatin Protein Expression}

In the present study, Alloxan treated group rats significantly showed the reduction of testicular Visfatin protein expression compared to the control group. However, the treatment of GA significantly $(\mathrm{P}<0.05)$ increased testicular Visfatin protein expression compared to the diabetic rat group (Figure 5A). 


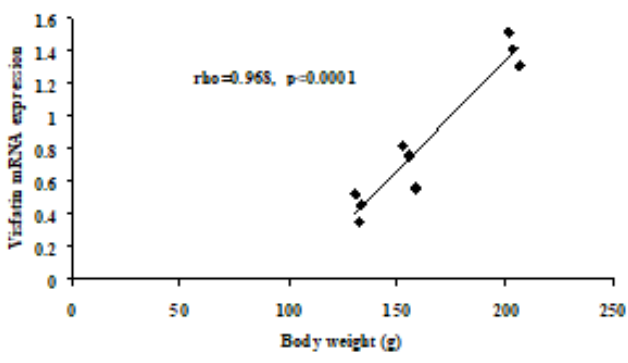

A

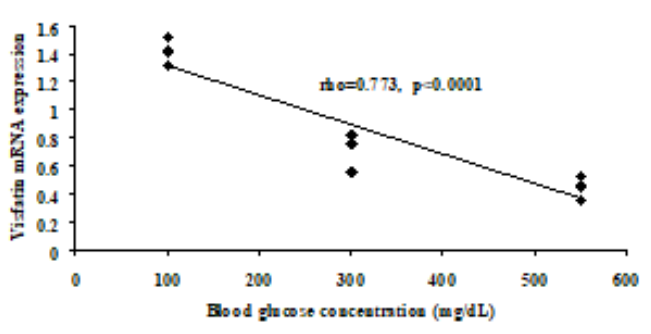

C

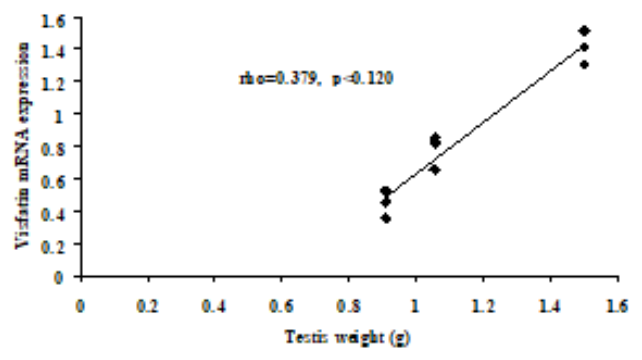

B

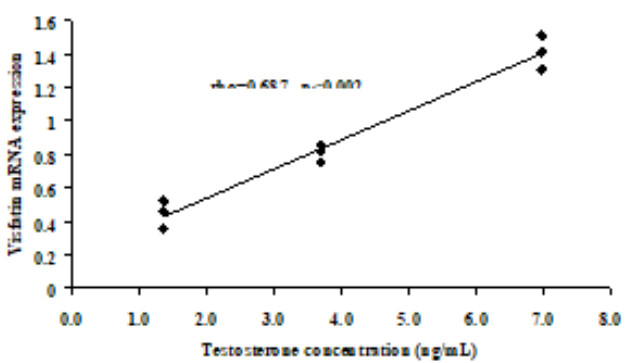

D

Figure 3.

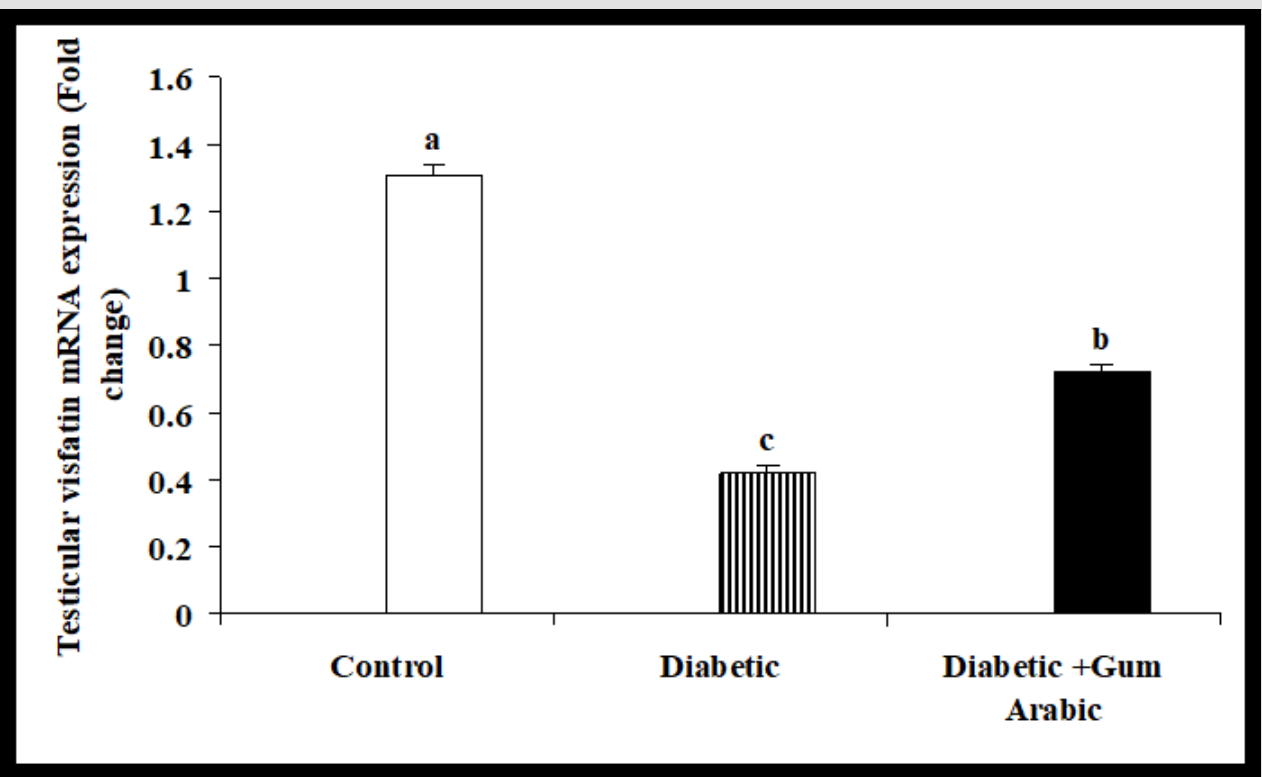

Figure 4 .

\section{Histopathological Features}

Histological features in testis of the control group revealed normal cytology of the testis with no visible degenerative changes
(Figure 6A). The testis of diabetic rats showed obvious degenerative changes with vacoulations (Figure 6B). However, the treatment of GA slightly protected the testis of diabetic rats from degenerative damages compared to control and diabetic rats (Figure 6C). 


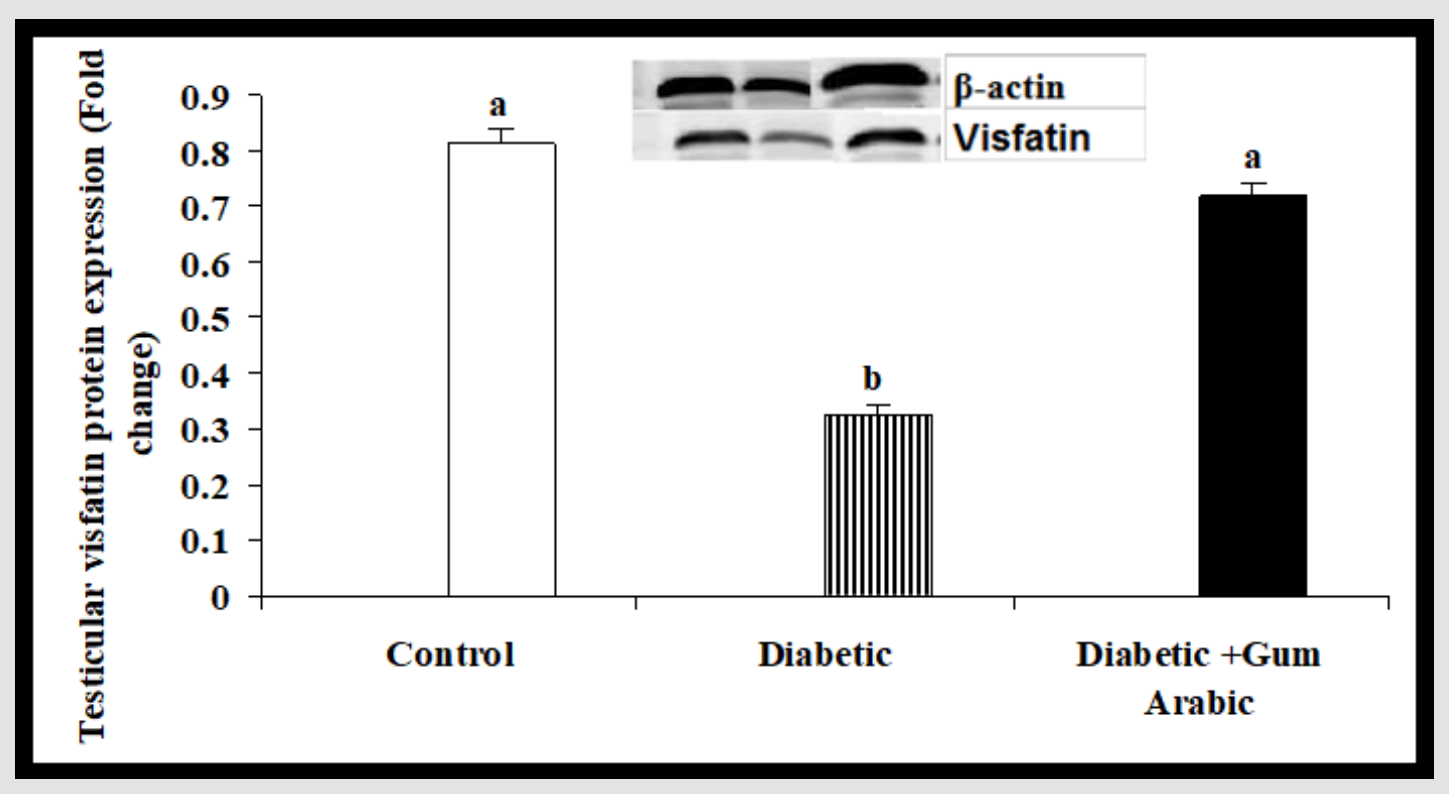

Figure 5.

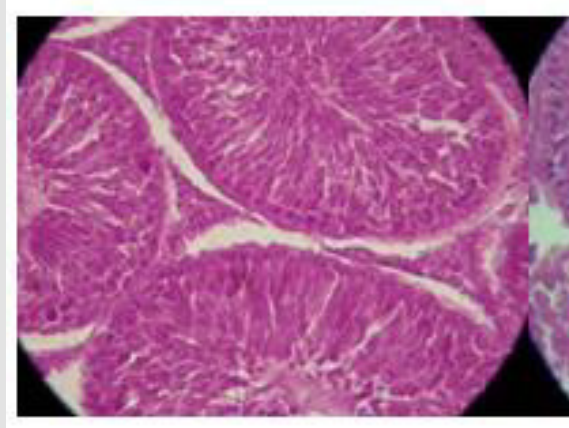

A

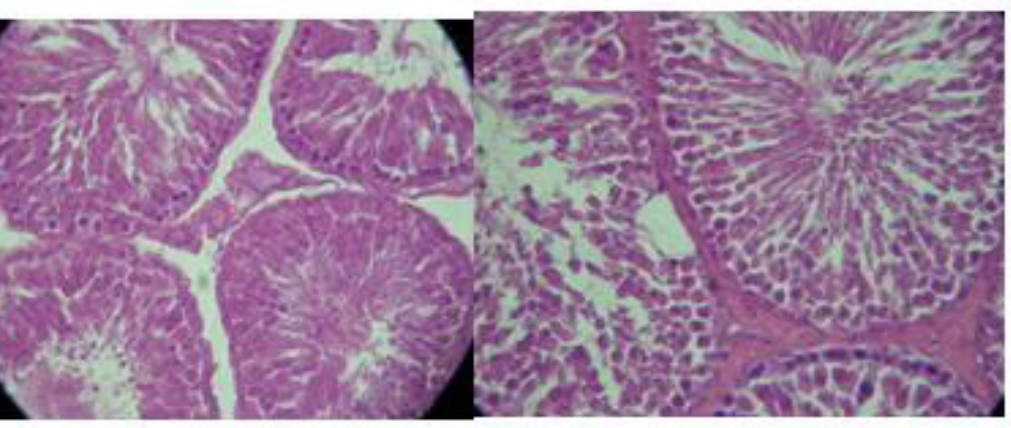

B
C

Figure 6 .

\section{Discussion}

Diabetes mellitus (DM) is a potential pandemic metabolic disorder causes dysfunction of reproductive performance [67]. In the present study, the treatment of Gum Arabic (GA) decreased food intake associated with decreases in body weight and testis weight. These findings are in line with previous studies that the treatment of dietary fibre decreased food intake and decreased body weight in mice [67-69]. The decreases in food intake or body weight by GA could be due to the fact that a number of studies revealed that the dietary fiber enhanced satiation and satiety [70], changed the glycaemic index [71], influenced the gastric emptying, and secretion of gastric hormone [72] thus, it reduces body weight [67]. In addition, the supplementation of GA in the form of drinking water decreased blood glucose. These findings are consistent with our earlier studies that GA decreased blood glucose both in normal and diabetic rat $[73,74]$ or normal mice [61]. It is well documented that the consumption of GA inhibits absorption of glucose in the intestine through interaction of membrane abundance in sodium-glucose transporter 1(SGLT1) in mice [75]. However, the mechanism of underlying the reduction of blood glucose by GA is not yet fully elucidated, due to the lack of researches in this field. Several experimental studies documented that the induction of diabetes in animal models has impaired reproductive performance via decreasing testicular function thus caused male fertility [76]. In the present study, the treatment of GA increased sperm quality parameters in diabetic rat. These results confirm our previous studies which showed the improvement of semen quality by GA in diabetic rat model [77]. In addition, it was report that ginger (Zingiber officinale) a dietary fibre enhanced reproductive capacity via increasing semen quantity in diabetic rat [78]. Moreover, the histological changes of the testis showed marked degeneration in the testis of Alloxan-induced diabetic rats. However, the treatment of GA significantly protected the testis of diabetic rats from 
oxidative damage. These findings are agreed with those reported by that the GA supplementation protected various tissues including nephrotoxicity [79, 80], hepatotoxicity [81] and testis [77] in rat.

Visfatin, one of the adipokines [82], is present in a variety of tissues including the testis [83]. In the present study, the treatment of GA decreased blood glucose concentrations whereas, increased serum testosterone concentrations. Our findings are in line with previous studies that GA treatment decreased glucose concentration and production in rats $[60,61]$. In addition, lowfat intervention together with high-fiber increased testosterone levels after in human [84]. Conversely, intervention of low fat diet simultaneously with high fiber diet decreased serum and urine androgens in men [85]. In addition, treatment of GA significantly $(\mathrm{P}<0.05)$ increased testicular Visfatin mRNA expression associated with upregulation of Visfatin protein expression compared to the diabetic group. Testis of diabetic rats showed obvious degeneration whereas; slight degeneration was seen in GA treated rats compared to control. Visfatin mRNA expression revealed a positive correlation with body, testis weight and serum testosterone concentrations, while a negative correlation was observed with blood glucose concentrations.

\section{Conclusion}

Our findings conclude that GA may improve reproductive performance and it may be useful to meliorate the diabetic infertility complications in male.

\section{Conflict of Interest Statement}

All authors declare that they do not have any conflict of interest

\section{Acknowledgment}

This study is a collaboration projects from University of Nyala, Sudan; University “G. d'Annunzio" of Chieti-Pescara, Italy; Islamia University, Bahawalpur, Pakistan; Medical and Cancer Research Institute, Nyala, Sudan and National Ribat University, Khartoum, Sudan.

\section{References}

1. AG Atanasov, B Waltenberger, EM Pferschy Wenzig, T Linder, C Wawrosch, et al. (2015) Discovery and resupply of pharmacologically active plant-derived natural products: A review. Biotechnology advances 33(8): 1582-1614.

2. DA Dias, S Urban, U Roessner (2012) A historical overview of natural products in drug discovery. Metabolites 2(2): 303-336.

3. M McMacken, S Shah (2017) A plant-based diet for the prevention and treatment of type 2 diabetes. Journal of geriatric cardiology: JGC 14(5): 342-354.

4. W Kooti, M Farokhipour, Z Asadzadeh, D Ashtary Larky, M Asadi Samani (2016) The role of medicinal plants in the treatment of diabetes: a systematic review. Electronic physician 8(1):1832-1842.
5. E Rutebemberwa, M Lubega, SK Katureebe, A Oundo, F Kiweewa, et al. (2013) Use of traditional medicine for the treatment of diabetes in Eastern Uganda: a qualitative exploration of reasons for choice. BMC International Health and Human Rights 13: 1-1.

6. T van Andel, L Carvalheiro (2013) Why Urban Citizens in Developing Countries Use Traditional Medicines: The Case of Suriname. EvidenceBased Complementary and Alternative Medicine 2013: 13.

7. N Kumar, AK Singh (2015) Trends of male factor infertility, an important cause of infertility: A review of literature. Journal of human reproductive sciences 8(4): 191-196.

8. MC Inhorn, P Patrizio (2015) Infertility around the globe: new thinking on gender, reproductive technologies and global movements in the $21^{\text {st }}$ century. Human Reproduction Update 21(4): 411-426.

9. JA Katula, JK Kirk, CF Pedley, MR Savoca, VS Effoe, et al. (2017) The Lifestyle Intervention for the Treatment of Diabetes study (LIFT Diabetes): Design and baseline characteristics for a randomized translational trial to improve control of cardiovascular disease risk factors. Contemporary clinical trials 53: 89-99.

10. I Hameed, SR Masoodi, SA Mir, M Nabi, K Ghazanfar, et al. (2015) Type 2 diabetes mellitus: From a metabolic disorder to an inflammatory condition. World journal of diabetes 6(4): 598-612.

11. C Lans, L Taylor Swanson, R Westfall (2018) Herbal fertility treatments used in North America from colonial times to 1900, and their potential for improving the success rate of assisted reproductive technology. Reproductive biomedicine \& society online 5: 60-81.

12. GT Mbemya, LA Vieira, FG Canafistula, ODL Pessoa, APR Rodrigues (2017) Reports on in vivo and in vitro contribution of medicinal plants to improve the female reproductive function. Reprodução \& Climatério 32(2): 109-119.

13. RW Bussmann, A Glenn (2010) Medicinal plants used in Northern Peru for reproductive problems and female health. Journal of ethnobiology and ethnomedicine 6: 30 .

14. SL Chen, H Yu, HM Luo, Q Wu, CF Li, et al. (2016) Conservation and sustainable use of medicinal plants: problems, progress, and prospects. Chinese Medicine 11: 37.

15. HF Kaadaaga, J Ajeani, S Ononge, PE Alele, N Nakasujja, et al. (2014) Prevalence and factors associated with use of herbal medicine among women attending an infertility clinic in Uganda. BMC complementary and alternative medicine 14: 27-27.

16. S Canivell, R Gomis (2014) Diagnosis and classification of autoimmune diabetes mellitus. Autoimmun Rev 13(4-5): 403-407.

17. D Tripathy, AO Chavez (2010) Defects in Insulin Secretion and Action in the Pathogenesis of Type 2 Diabetes Mellitus. Current diabetes reports 10(3): 184-191.

18. A Rohmetra, R Tandon, A Jaiswal, R Rai, R Srivastava (2018) Orthodontic plight: Diabetes mellitus. International Journal of Oral Health Sciences 8(1): 13-18.

19. B Giri, S Dey, T Das, M Sarkar, J Banerjee, et al. (2018) Chronic hyperglycemia mediated physiological alteration and metabolic distortion leads to organ dysfunction, infection, cancer progression and other pathophysiological consequences: An update on glucose toxicity. Biomedicine \& Pharmacotherapy 107: 306-328.

20. L Long, H Qiu, B Cai, N Chen, X Lu, et al. (2018) Hyperglycemia induced testicular damage in type 2 diabetes mellitus rats exhibiting microcirculation impairments associated with vascular endothelial growth factor decreased via PI3K/Akt pathway. Oncotarget 9(4): 53215336.

21. S Prasad, RK Sajja, P Naik, L Cucullo (2014) Diabetes Mellitus and BloodBrain Barrier Dysfunction: An Overview. Journal of pharmacovigilance 


\section{2: $125-125$.}

22. ME Cooper, V Perkovic, JB McGill, PH Groop, C Wanner, et al. (2015) Kidney Disease End Points in a Pooled Analysis of Individual PatientLevel Data from a Large Clinical Trials Program of the Dipeptidyl Peptidase 4 Inhibitor Linagliptin in Type 2 Diabetes. Am J Kidney Dis 66(3): 441-449.

23. JA Beckman, F Paneni, F Cosentino, MA Creager (2013) Diabetes and vascular disease: pathophysiology, clinical consequences, and medical therapy: part II. Eur Heart J 34(31): 2444-2452.

24. MK Adjemian, RJ Volpe, J Adjemian (2015) Relationships between Diet, Alcohol Preference, and heart disease and Type 2 Diabetes among Americans. PLoS One 10(5): e0124351.

25. KN Chandrashekar, Muralidhara (2009) Evidence of oxidative stress and mitochondrial dysfunctions in the testis of prepubertal diabetic rats. Int J Impot Res 21(3): 198-206.

26. RJ Aitken, SD Roman (2008) Antioxidant systems and oxidative stress in the testes. Adv Exp Med Biol 636: 154-171.

27. D Dymkowska, B Drabarek, P Podszywalow Bartnicka, J Szczepanowska, K Zablocki (2014) Hyperglycaemia modifies energy metabolism and reactive oxygen species formation in endothelial cells in vitro. Arch Biochem Biophys 542: 7-13.

28. F Giacco, M Brownlee (2010) Oxidative stress and diabetic complications. Circulation research 107(9): 1058-1070.

29. M Brownlee (2005) The Pathobiology of Diabetic Complications: A Unifying Mechanism. Diabetes 54(6): 1615-1625.

30. S Nowsheen, ES Yang (2012) The Intersection Between DNA Damage Response and Cell Death Pathways. Experimental oncology 34(3): 243254.

31. FA Matough, SB Budin, ZA Hamid, N Alwahaibi, J Mohamed (2012) The role of oxidative stress and antioxidants in diabetic complications. Sultan Qaboos Univ Med J 12(1): 5-18.

32. L Rato, MG Alves, TR Dias, JE Cavaco, PF Oliveira (2015) Testicular Metabolic Reprogramming in Neonatal Streptozotocin-Induced Type 2 Diabetic Rats Impairs Glycolytic Flux and Promotes Glycogen Synthesis. Journal of Diabetes Research 2015: 13.

33. S La Vignera, R Condorelli, E Vicari, RD Agata, AE Calogero (2012) Diabetes mellitus and sperm parameters. Journal of andrology 33(2): 145-153.

34. J Liu, Y Wang, L Gong, C Sun (2015) Oxidation of glyceraldehyde3-phosphate dehydrogenase decreases sperm motility in diabetes mellitus. Biochem Biophys Res Commun 465(2): 245-248.

35. IM Agbaje, DA Rogers, CM McVicar, N McClure, AB Atkinson, et al. (2007) Insulin dependant diabetes mellitus: implications for male reproductive function. Hum Reprod 22(7): 1871-1877.

36. V Bartak, M Josifko, M Horackova (1975) Juvenile diabetes and human sperm quality. Int J Fertil 20(1): 30-32.

37. FT Murray, DF Cameron, JM Orth, MJ Katovich (1985) Gonadal dysfunction in the spontaneously diabetic BB rat: alterations of testes morphology, serum testosterone and LH. Horm Metab Res 17(10): 495501.

38. J Ballester, MC Munoz, J Dominguez, T Rigau, JJ Guinovart, et al. (2004) Insulin-dependent diabetes affects testicular function by FSH- and LHlinked mechanisms. J Androl 25(5): 706-719.

39. AA Al Hayek, YS Khader, S Jafal, N Khawaja, AA Robert, et al. (2013) Prevalence of low testosterone levels in men with type 2 diabetes mellitus: a cross-sectional study. J Family Community Med 20(3): 179186.
40.00 Elekofehinti, OC Ejelonu, JP Kamdem, OB Akinlosotu, A Famuti, et al. (2018) Discovery of potential visfatin activators using in silico docking and ADME predictions as therapy for type 2 diabetes. Beni-Suef University Journal of Basic and Applied Sciences 7(2): 241-249.

41. E Adeghate (2008) Visfatin: structure, function and relation to diabetes mellitus and other dysfunctions. Current medicinal chemistry 15(8): 1851-1862.

42. YS Kang, MH Lee, HK Song, JE Kim, JY Ghee, et al. (2016) Chronic Administration of Visfatin Ameliorated Diabetic Nephropathy in Type 2 Diabetic Mice. Kidney and Blood Pressure Research 41: 311-324.

43. ED Rosen, BM Spiegelman (2006) Adipocytes as regulators of energy balance and glucose homeostasis. Nature 444(7121): 847-853.

44. R Yang, L Chang, M Wang, H Zhang, J Liu, et al. (2014) MAPK pathway mediates the induction of visfatin in neonatal SD rat cardiomyocytes pretreated with glucose. Biomedical reports 2: 282-286.

45. K Segawa, A Fukuhara, N Hosogai, K Morita, Y Okuno, et al. (2006) Visfatin in adipocytes is upregulated by hypoxia through HIF1 $\alpha$-dependent mechanism. Biochemical and biophysical research communications 349(3): 875-882

46. MH El Samahi, NA Ismail, RM Matter, A Selim, AA Ibrahim, et al. (2017) Study of Visfatin Level in Type 1 Diabetic Children and Adolescents. Open access Macedonian journal of medical sciences 5(3): 299-304.

47. F Kabir, FA Jahan, I Khan, MO Faruque, Z Hassan, et al. (2015) Increased concentration of circulating visfatin associates with post-challenged hyperglycaemia and insulin resistance in IGT subjects. Journal of Taibah University Medical Sciences 10(4): 481-487.

48. D Taşkesen, B Kirel, T Us (2012) Serum visfatin levels, adiposity and glucose metabolism in obese adolescents. Journal of clinical research in pediatric endocrinology 4(2): 76-81.

49. P Saddi Rosa, CSV Oliveira, FMA Giuffrida, AF Reis (2010) Visfatin, glucose metabolism and vascular disease: a review of evidence. Diabetology \& Metabolic Syndrome 2: 21.

50. MP Chen, FM Chung, DM Chang, JC Tsai, HF Huang, et al. (2006) Elevated plasma level of visfatin/pre-B cell colony-enhancing factor in patients with type 2 diabetes mellitus. J Clin Endocrinol Metab 91(1): 295-299.

51. TF Chan, YL Chen, CH Lee, FH Chou, LC Wu, et al. (2006) Decreased Plsma Visfatin Concentrations in Women with Gestational Diabetes Mellitus. Journal of the Society for Gynecologic Investigation 13(5): 364-367.

52. M Olszanecka Glinianowicz, P Kocelak, M Nylec, J Chudek, B Zahorska Markiewicz (2012) Circulating visfatin level and visfatin/insulin ratio in obese women with metabolic syndrome. Archives of medical science: AMS 8(2): 214-218.

53. P Saddi Rosa, CS Oliveira, FM Giuffrida, AF Reis (2010) Visfatin, glucose metabolism and vascular disease: a review of evidence. Diabetol Metab Syndr 2: 21.

54. Z Liang, Y Wu, J Xu, Q Fang, D Chen (2016) Correlations of serum visfatin and metabolisms of glucose and lipid in women with gestational diabetes mellitus. Journal of diabetes investigation 7(2): 247-252.

55. R Chawla, GR Patil (2010) Soluble Dietary Fiber, Comprehensive Reviews in Food Science and Food Safety 9(2): 178-196.

56. BN Chikamai, WB Banks, DMW Anderson, W Weiping (1996) Processing of gum arabic and some new opportunities. Food Hydrocolloids 10(3): 309-316.

57. VD Prajapati, GK Jani, NG Moradiya, NP Randeria (2013) Pharmaceutical applications of various natural gums, mucilages and their modified forms. Carbohydrate polymers 92(2): 1685-1699.

58. BH Ali, A Ziada, G Blunden (2009) Biological effects of gum arabic: a review of some recent research. Food and chemical toxicology: an 
international journal published for the British Industrial Biological Research Association 47(1): 1-8.

59. RE Mohamed, MO Gadour, I Adam (2015) The lowering effect of Gum Arabic on hyperlipidemia in Sudanese patients. Front Physiol 6: 160.

60. AA Ahmed, JS Fedail, HH Musa, TH Musa, AZ Sifaldin (2016) Gum Arabic supplementation improved antioxidant status and alters expression of oxidative stress gene in ovary of mice fed high fat diet. Middle East Fertility Society Journal 21(2): 101-108.

61. JL Hu, SP Nie, N Li, FF Min, C Li, et al. (2014) Effect of gum arabic on glucose levels and microbial short-chain fatty acid production in white rice porridge model and mixed grain porridge model. Journal of agricultural and food chemistry 62(27): 6408-6416.

62. R Babiker, K Elmusharaf, MB Keogh, AM Saeed (2018) Effect of Gum Arabic (Acacia Senegal) supplementation on visceral adiposity index (VAI) and blood pressure in patients with type 2 diabetes mellitus as indicators of cardiovascular disease (CVD): a randomized and placebocontrolled clinical trial. Lipids Health Dis 17(1): 56.

63. AO Adeyi, BA Idowu, CF Mafiana, SA Oluwalana, OL Ajayi, et al. (2012) Rat model of food-induced non-obese-type 2 diabetes mellitus: comparative pathophysiology and histopathology. Int J Physiol Pathophysiol Pharmacol 4(1): 51-58.

64. AA Ahmed, W Ma, Y Ni, Q Zhou, R Zhao (2014) Embryonic exposure to corticosterone modifies aggressive behavior through alterations of the hypothalamic pituitary adrenal axis and the serotonergic system in the chicken. Hormones and Behavior 65(2): 97-105.

65. KJ Livak, TD Schmittgen (2001) Analysis of relative gene expression data using real-time quantitative PCR and the 2(-Delta Delta C(T)) Method. Methods 25(4): 402-408.

66. MK Ali, KR Siegel, E Chandrasekar, R Tandon, PA Montoya, et al. (2017) Diabetes: An Update on the Pandemic and Potential Solutions. In: D Prabhakaran, S Anand, TA Gaziano, JC Mbanya, Y Wu, R Nugent (Eds.)., Cardiovascular, Respiratory, and Related Disorders, Washington (DC), USA.

67. M Chandalia, A Garg, D Lutjohann, K von Bergmann, SM Grundy, et al. (2000) Beneficial effects of high dietary fiber intake in patients with type 2 diabetes mellitus. N Engl J Med 342(19): 1392-1398.

68. JM Lattimer, MD Haub (2010) Effects of dietary fiber and its components on metabolic health. Nutrients 2(12): 1266-1289.

69. AA Ahmed (2018) 16 - Health Benefits of Gum Arabic and Medical Use. In: AA Mariod (Edt.)., Gum Arabic, Academic Press, USA, pp. 183-210.

70. B Burton Freeman (2000) Dietary fiber and energy regulation. J Nutr 130(2): 272S-275S.

71. AW Barclay, VM Flood, E Rochtchina, P Mitchell, JC Brand Miller (2007) Glycemic index, dietary fiber, and risk of type 2 diabetes in a cohort of older Australians. Diabetes Care 30(11): 2811-2813.

72. MO Weickert, AF Pfeiffer (2008) Metabolic effects of dietary fiber consumption and prevention of diabetes. J Nutr 138(3): 439-442.

\section{ISSN: 2574-1241}

DOI: $10.26717 /$ BJSTR.2021.37.006041

Abdelkareem A Ahmed. Biomed J Sci \& Tech Res

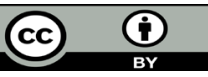

This work is licensed under Creative Commons Attribution 4.0 License

Submission Link: https://biomedres.us/submit-manuscript.php
73. AA Ahmed, JS Fedail, HH Musa, AA Kamboh, AZ Sifaldin, et al. (2015) Gum Arabic extracts protect against hepatic oxidative stress in alloxan induced diabetes in rats. Pathophysiology: the official journal of the International Society for Pathophysiology 22(4): 189-194.

74. R Gahler, G Grover, R Reimer, S Wood (2011) Effects of the Soluble Fiber Complex PolyGlycopleX ${ }^{\circledast}$ on Glucose Homeostasis and Body Weight in Young Zucker Diabetic Rats. Frontiers in pharmacology 2.

75. O Nasir, F Artunc, K Wang, R Rexhepaj, M Foller, et al. (2010) Downregulation of mouse intestinal $\mathrm{Na}(+)$-coupled glucose transporter SGLT1 by gum arabic (Acacia Senegal). Cell Physiol Biochem 25(2-3): 203-210.

76. L Navarro Casado, MA Juncos Tobarra, M Chafer Rudilla, LI de Onzono, JA Blazquez Cabrera, et al. (2010) Effect of experimental diabetes and STZ on male fertility capacity. Study in rats. Journal of andrology 31(6): 584-592.

77. JS Fedail, AA Ahmed, HH Musa, E Ismail, AZ Sifaldin, et al. (2016) Gum arabic improves semen quality and oxidative stress capacity in alloxan induced diabetes rats. Asian Pacific Journal of Reproduction 5(5): 434441.

78.Z Ghlissi, R Atheymen, MA Boujbiha, Z Sahnoun, F Makni Ayedi, et al. (2013) Antioxidant and androgenic effects of dietary ginger on reproductive function of male diabetic rats. International journal of food sciences and nutrition 64(8): 974-978.

79. AA Al Majed, AM Mostafa, AC Al Rikabi, OA Al Shabanah (2002) Protective effects of oral arabic gum administration on gentamicin-induced nephrotoxicity in rats. Pharmacological research 46(5): 445-451.

80. 0 Nasir (2013) Renal and extrarenal effects of gum arabic ( Acacia senegal )--what can be learned from animal experiments? Kidney \& blood pressure research 37(4-5): 269-279.

81. OL Erukainure, OAT Ebuehi, FO Adeboyejo, O0 Oladunmoye, M Aliyu, et al. (2015) Short-Term Feeding of Fibre-Enriched Biscuits: Protective Effect against Hepatotoxicity in Diabetic Rats. Biochemistry Research International 2015: 868937.

82. F Dutheil, BA Gordon, G Naughton, E Crendal, D Courteix, et al. (2018) Cardiovascular risk of adipokines: a review. The Journal of international medical research 46(6): 2082-2095.

83. M Blüher (2014) Adipokines - removing road blocks to obesity and diabetes therapy. Molecular metabolism 3(3): 230-240.

84. EJ Schaefer, S Lamon Fava, D Spiegelman, JT Dwyer, AH Lichtenstein, et al. (1995) Changes in plasma lipoprotein concentrations and composition in response to a low-fat, high-fiber diet are associated with changes in serum estrogen concentrations in premenopausal women. Metabolism: clinical and experimental 44(6): 749-756.

85. C Wang, DH Catlin, B Starcevic, D Heber, C Ambler, et al. (2005) Lowfat high-fiber diet decreased serum and urine androgens in men. J Clin Endocrinol Metab 90(6): 3550-3559.

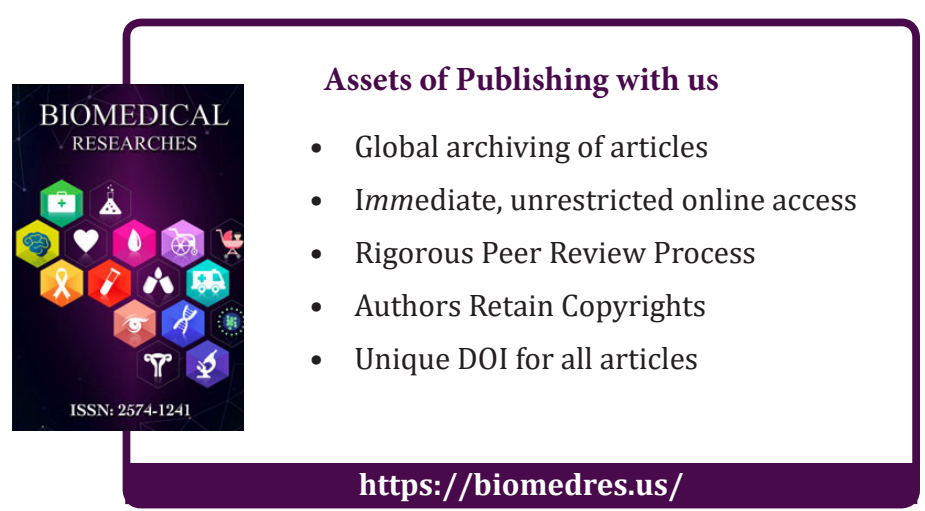

